\title{
Implementing selective-prevention primary care interventions targeting cardio-metabolic diseases in five European countries: the SPIM-EU project
}

Christos D Lionis ( $\square$ lionis@galinos.med.uoc.gr)

Clinic of Social and Family Medicine

Marilena Anastasaki

School of Medicine, University of Crete, Greece

Antonios Bertsias

School of Medicine, University of Crete, Greece

Agapi Angelaki

School of Medicine, University of Crete, Greece

Axel C Carlsson

Karolinska Institutet

Hrafnhildur Gudjonsdottir

Region Stockholm

Per Wändell

Karolinska Institutet

Anders L Sonderlund

University of Southern Denmark

Trine Thilsing

University of Southern Denmark

Jens Søndergaard

University of Southern Denmark

Bohumil Seifert

Charles University

Norbert Kral

Charles University

Niek de Wit

Julius Center, The Netherlands

Monika Hollander

Julius Center, The Netherlands

Joke Korevaar

Netherlands Institute, Utrecht

François G Schellevis 
NIVEL, The Netherlands

\section{Research article}

Keywords: cardio-metabolic diseases, cardio-vascular diseases, feasibility study, prevention, primary care, risk reduction

Posted Date: April 24th, 2020

DOI: https://doi.org/10.21203/rs.3.rs-18773/v1

License: (1) (1) This work is licensed under a Creative Commons Attribution 4.0 International License. Read Full License 


\section{Abstract \\ Background}

Cardio-metabolic diseases are the most common cause of death worldwide. Implementing selective prevention strategies has proven a substantial challenge, especially in primary care.

\section{Objectives}

As part of a collaborative European study, this paper aims to assess the implementation of primary care selective prevention interventions in the Czech Republic, Denmark, Greece, the Netherlands and Sweden. We sought to determine participants' cardio-metabolic risk profile, as well as their evaluation of the intervention in terms of feasibility and impact in promoting a healthy lifestyle.

\section{Methods}

A selective prevention intervention, including patient invitation and cardio-vascular risk assessment using country-adjusted tools, was implemented. Eligible participants were primary care patients, 40-65 years of age, without any diagnosis of cardio-metabolic disease. Main outcomes included intervention acceptance and completion rates. Patient demographics, lifestyle-related cardio-metabolic risk factors, and opinions on intervention feasibility were recorded. Findings are summarized descriptively.

\section{Results}

In each country, 200 patients were invited to participate in the study. Acceptance rates varied from $19.5 \%$ $(n=39 / 200)$ in Sweden to $100 \%$ in the Czech Republic $(n=200 / 200)$. Risk assessment completion rates ranged from $65.4 \%(n=70 / 107)$ in Greece to $100 \%(n=39 / 39)$ in Sweden. Twelve individuals $(6.9 \%)$ were identified as being at high risk of cardio-vascular disease in the Czech Republic, five (8.6\%) in Denmark, eight (11.4\%) in Greece, 21 (36.8\%) in the Netherlands and none (0\%) in Sweden. On a ten-point scale, the median (25\%-75\% quartile) of participant-reported intervention feasibility ranged from 7.4 (6.9-7.8) in Greece to 9.2 (8.2-9.9) in Sweden. Willingness to change lifestyle exceeded $80 \%$ in all countries, with the desire for better health representing the main motivating factor for more than half of the participants.

\section{Conclusions}

Although substantial variations in patient cardio-metabolic risk profile and intervention receptiveness were observed, our findings add to existing evidence regarding the implementation of selective prevention programs in European primary care and can be used as part of future cardio-metabolic risk reduction strategies. 


\section{Background}

Cardio-metabolic disease (CMD), including cardio-vascular disease (CVD) and type-II diabetes mellitus (T2DM), represents the most common cause of death worldwide, accounting for more than 17,3 million deaths globally every year $(1,2)$. Although statistics show a significant decline of CVD morbidity and mortality in most European countries, CMD mortality, quality of life, and health care expenditure are still considerably cumbersome (1). In light of the fact that factors such as diet, exercise, smoking, and alcohol consumption affect CMD risk (3-5), however, current evidence indicates that up to $80 \%$ of CMDs can be prevented or delayed through lifestyle changes (6).

The United States Institute of Medicine classifies preventive strategies in four categories: indicated prevention, care-related prevention, universal prevention, and selective prevention (7). Selective prevention aims to identify high-risk, asymptomatic individuals in the general population and offer them preventive strategies. Evidence from modeling studies and systematic reviews suggests that selective prevention of CMD can help reduce the burden of disease in the general population $(8,9)$. In terms of CMD-preventive efforts, primary care and general practitioners (GPs) are on the front lines, with the European Society of Cardiology (ESC) guidelines stating that "GPs have a unique role in identifying individuals at risk of, but without established CVD, and assessing their eligibility for intervention"(6).

The present study is part of the European SPIM-EU project (http://spimeu.org/). SPIM-EU seeks to contribute to the reduction of CMD morbidity and mortality in Europe by testing the feasibility of evidencebased selective prevention strategies and providing comprehensive tools for their application in primary care (10). Within the framework of SPIM-EU an expert consensus meeting has been conducted and a set of statements representing the key characteristics of selective CMD prevention has been proposed in order to develop a universal concept of selective CMD prevention that can guide implementation within European primary care (11). The overall aim of the present study was to assess the feasibility of CMD selective prevention in five considerably different European primary care settings (Czech Republic, Denmark, Greece, Netherlands and Sweden), with special focus on patient participation and acceptance rates. We also sought to report on participants' CMD profile and CVD-risk and record their evaluation of the intervention in terms of feasibility and efficacy in promoting healthy behaviors.

\section{Methods}

\section{Design and setting}

This was a descriptive study reporting on the feasibility of a selective prevention intervention. Outcomes were summarized using descriptive statistics.

The design and critical determinants of the selective prevention intervention were informed by a consensus meeting with an international panel of 14 experts exploring the evidence from systematic literature reviews and surveys conducted within SPIM-EU (11). The present selective prevention intervention included the invitation and CVD-risk assessment of primary care patients and was 
implemented in the Czech Republic, Denmark, Greece, the Netherlands and Sweden. In all countries, primary care practices were purposively selected (with the exception of the Netherlands) as study sites: ten practices in the Czech Republic (average practice size: 1900 persons), two in Denmark (average practice size: 1600 persons), three in Greece (average practice size: 1500 persons), five in the Netherlands (average practice size: 2350 persons), and one in Sweden (20,000 listed persons).

\section{Participants}

Participants were patients of the selected primary care practices in the five countries. In the Netherlands and Denmark participants were randomly selected, while in the other settings consecutively.

Patients were eligible to participate if they were between 40-65 years of age and had not been diagnosed with a CMD, such as hypertension, CVD, T2DM, chronic renal disease, and/or hypercholesterolemia. In Denmark, the Netherlands and Sweden eligible participants were neither diagnosed with nor in current treatment for CMD.

Since this was a descriptive study assessing implementation feasibility, patient-level sample size estimation was not performed. Rather, a convenience sample of 200 participants per country was set as recruitment goal.

\section{Procedures and outcomes}

Details regarding procedural aspects per participating county are presented in the Supplementary Table. The overall selective prevention intervention consisted of patient invitation and CVD-risk assessment and was delivered in a similar manner in all countries, as follows:

1. Identification and invitation of 200 participants: Eligible participants were identified via primary care practice patient lists. They were invited to the study either personally, by the staff at the practice (Czech Republic, Greece, the Netherlands, Sweden), or via their digital mailbox (a digital mail-system provided by the government for secure and direct communication between individuals, public authorities and other trusted organizations in Denmark). The recruitment period ran from April through October 2018 at all sites.

2. Initial assessment of participant CMD-risk factors: An online questionnaire developed based on the European Social Survey (http://www.europeansocialsurvey.org) was used. The questionnaire was either administered to participants by the practice personnel or research assistants during a face-toface consultation (Czech Republic, Greece, the Netherlands, Sweden), or completed by participants via their digital mailbox (Denmark). The questionnaire recorded demographic characteristics (age, gender, education, work status, insurance, income) and lifestyle-related CMD-risk factors (smoking, alcohol consumption, physical activity, nutrition).

3. Comprehensive CVD-risk assessment: Each country selected a tool for CVD-risk measurement, based on the ESC or national guidelines (6). Locally validated tools used in clinical practice of each country were selected to facilitate the local adaptation of the intervention. In the Czech Republic and Greece, 
country-adjusted versions of the European Heart SCORE were used (12). In Sweden, Svenska Score (or SCORE Sweden) was selected (13). In Denmark and the Netherlands, the modified Heartscore BMI score (14) and the Dutch Prevention Consultation Cardiometabolic Risk (PC CMR) (15) were used respectively.

4. Participant evaluation of the intervention: On a ten-point Likert scale, participants were asked to assess the relevance, usefulness, and feasibility of the selective prevention intervention, as well as the extent to which it encouraged a healthier lifestyle. Participants' willingness to change risk behavior, as well as any encountered barriers to lifestyle-style modification, were also assessed.

Upon intervention completion, participants were verbally informed about their CVD-risk and were provided with practical advice on how to reduce it.

Study outcomes (per country) were:

1. Numbers and proportions of patients who accepted the invitation and completed their CMD-risk profiling (feasibility).

2. Numbers and proportions of participants who completed the comprehensive CVD-risk assessment (feasibility).

3. Participant-reported intervention relevance, usefulness, feasibility and impact in pursuing a healthier lifestyle, along with respective barriers (evaluation).

\section{Results}

\section{Recruitment}

Supplementary Figure shows the study flowchart. As per recruitment goal, 200 eligible individuals were identified and invited to participate in the selective prevention intervention in each country (total $N=1,000$ ). In total, less than half of invited individuals $(47.4 \%, n=474)$ accepted the invitation. Acceptance rates ranged from 19.5\% $(n=39)$ in Sweden to $100 \%(n=200)$ in the Czech Republic. Sweden had the highest risk-assessment completion rate $(100 \%, n=39)$ among all countries, while Greece had the lowest $(65.4 \%$, $\mathrm{n}=70)$. Across all sites, there was an $84.2 \%(n=399)$ risk-assessment completion rate.

\section{Participants}

Participants' demographics are summarized in Table 1. Women were over-represented in all countries [Czech Republic: 60.5\% ( $n=121)$, Greece: 59.8\% ( $n=34)$, Netherlands: 54.5\% ( $n=36)$, Sweden: $69.2 \%(n=27)]$, apart from Denmark $(46.8 \%, n=29)$. Mean age of participants ranged from $50( \pm 8.8)$ years in the Czech Republic to $55.5( \pm 6.3)$ years in Denmark.

In all countries, except for Greece, most participants had university education [Czech Republic: 82.3\% ( $n=63)$, Denmark: 83.4\% ( $n=45)$, Netherlands: 80.3\% ( $n=53)$, Sweden: 100\% ( $n=39)$, while in Greece the majority of participants had completed secondary education $(48.6 \%, n=52)$. Most participants were 
working full-time and were covered by health insurance. In the Czech Republic and Sweden most participants reported an income above the country average [42.2\% $(n=84)$ and $61.5 \%(n=24)$, respectively]. In the Netherlands, most participants had an income equal to the national average $(53.8 \%, n=35)$, while in Greece the reported income was lower than the average $(62.6 \%, n=67)$.

[Table 1 approximately here]

\section{CMD-risk profiling}

CMD-risk factors related to participant lifestyles are presented in Table 2. Daily smoking ranged from $43 \%(n=46)$ in Greece to 3.1\% $(n=2)$ in the Netherlands. Long-term ex-smokers (quit over 6 months ago) accounted for $34.4 \%(n=22)$ in the Netherlands, 33.3\% in Denmark ( $n=20), 20.5 \%$ in Sweden $(n=8)$, $17 \%(n=34)$ in the Czech Republic and 15\% in Greece $(n=16)$. Rates of never-smoking ranged from $32.7 \%$ $(n=35)$ in Greece to $71.8 \%(n=28)$ in Sweden.

The median (IQR) number of standard alcoholic beverages consumed weekly reached [7(9)] in Greece, followed by Denmark [4(8)], Sweden [3(5)], Netherlands [2(7)], and the Czech Republic [2(6)]. Additionally, more than $10 \%$ of participants in all countries stated that they drink four (for women) or five (for men) standard drinks on a single occasion at least once weekly.

Rates of sedentary lifestyle ranged from $8.1 \%(n=5)$ in Denmark to $19.6 \%(n=21)$ in Greece. Roughly one out of four participants were classified as under-active (light or moderate exercise, not weekly) in the Czech Republic (31.6\%, $n=62)$, Denmark $(25 \%, n=12)$, the Netherlands $(20 \%, n=13)$ and in Sweden $(25.6 \%, n=10)$, while in Greece the rate was almost double $(48.1 \%, n=51)$.

Daily vegetable consumption was reported by most participants in Sweden $(82 \%, n=32)$, the Netherlands $(80 \%, n=52)$, Denmark $(61.3 \%, n=38)$, but not in the Czech Republic $(44.2 \%, n=88)$ and Greece $(12.1 \%, n=13)$. In all countries, daily fruit consumption was reported by half or more of participants, apart from Greece where the rate was 21.5\% ( $\mathrm{n}=23)$. In the Czech Republic, Denmark, and Greece, most participants reported fish consumption a few times per month [62.1\% $(n=123), 50 \%(n=31)$ and $67.3 \%$ $(\mathrm{n}=72)$ respectively].

[Table 2 approximately here]

CVD-risk assessment

Table 3 presents CVD-risk scores for participants who completed the risk assessment tool used in each country. The median (25\%-75\% quartiles) of the country-adjusted European Heart SCORE was 1 (0-3) in Greece and 1 (0-2) in the Czech Republic. The median of Svenska score in Sweden was, remarkably, zero [0 (0-1)]. In Greece, $11.4 \%(n=8)$ of participants were found with increased CVD-risk (SCORE $\geq 5 \%$ ). Respective rates for Czech Republic and Sweden were 6.9\% ( $n=21)$ and zero. In Greece and the Czech Republic, $4.3 \%(n=3)$ and $2.3 \%(n=4)$ of participants respectively were classified in the highest CVD-risk category (SOCRE $\geq 10 \%$ ). In Denmark, the median (25\%-75\%) of the modified Heartscore BMI score was 2 
(1-3), with $8.6 \%(n=5)$ of participants classified at high CVD-risk. In the Netherlands, the median (25\%-75\%) PC CMR score was 22 (13.5-39.5), with 21 (36.8\%) participants found to be at high risk.

[Table 3approximately here]

\section{Participant evaluation of the intervention}

Figure 1 shows participants' evaluation of the selective prevention process assessed on a ten-point scale. In Sweden, intervention feasibility was assessed with the highest scores [median (25\%-75\% quartile): 9.2 $(8.2$ - 9.9)], while usefulness received the lowest scores [median (25\%-75\%): 6.1 (5 - 7.4)]. Greek participants assessed intervention's ability to encourage a healthier lifestyle with the highest scores [7.6 (7.1-7.9)] and its relevance the lowest [5.9 (5.5-7.7)]. In the Czech Republic all process evaluation dimensions received similar assessments, with median scores (25\% - 75\%) ranging from 7.2 (5.1 - 8.6) for relevance to 7.5 (6.2 - 9.2) for usefulness. Participants in Denmark and the Netherlands did not evaluate the risk assessment intervention, despite their invitation to do so.

[Figure 1 approximately here]

\section{Perception and barriers towards lifestyle modification}

In response to the risk assessment, the vast majority of participants in the Czech Republic (84.5\%, $n=147)$, Greece $(92.8 \%, n=64)$ and Sweden $(82.1 \%, n=32)$ reported they were willing to change their lifestyle in order to reduce their CMD-risk (Figure 2A). The main motivation behind this willingness was related to their desire for better health [Czech Republic: 71.3\% ( $n=124)$, Greece: 61.4\% $(n=43)$, Sweden: $61.5 \%(n=24)]$. A secondary reason for behavioral change specific to the Czech Republic was the possibility of having an increased CMD-risk $(31 \%, n=51)$, while in Greece it was the doctor's motivation to do so $(21.4 \%, n=15)$. In Sweden, the possibility of having an increased CMD-risk was the only secondary reason for behavioral change $(61.5 \%, \mathrm{n}=24)$. Participants in Denmark and the Netherlands did not respond to the above questions.

About one out of three Czech participants $(34.5 \%, \mathrm{n}=59)$ stated that they had encountered barriers in their attempt to change their lifestyle (Figure 2B). The equivalent rates were $12.8 \%(n=9)$ in Greece and $15.4 \%(n=6)$ in Sweden. Lack of time $(37.3 \%, n=22)$ and motivation $(35.6 \%, n=21)$ were identified as main barriers among the 59 Czech participants who had encountered barriers in their lifestyle-change attempt. In Greece, all nine (100\%) participants stated that they had tried but found it too difficult to start a healthier lifestyle. Other barriers reported by Greek participants included lack of budget $(66.6 \%, n=6)$, time $(44.4 \%, n=4)$, and knowledge about where to start $(33.3 \%, n=3)$. In Sweden four out of six $(66.7 \%)$ participants who reported barriers to lifestyle change, gave other reasons for not changing lifestyle, followed by having tried but finding it too difficult $(50 \%, n=3)$ and lack of motivation $(33.3 \%, n=2)$.

[Figure 2 approximately here]

\section{Discussion}


Our study showed the substantial cross-country variations in the implementation of the selective CMD prevention intervention, as well as in participant receptiveness. These variations could be interpreted in terms of the differences between the specific primary care systems included in our study and, as such, underline the necessity for European health policies and CMD prevention strategies.

Another important finding concerns the substantial differences between study participants regarding various lifestyle factors. Participants from Greece, followed by the Czech Republic, presented the most unfavorable health profile which was also reflected in their CVD-risk scores. This finding is in agreement with the international statistics and warrants further attention (16). Remarkably, no individuals with elevated CVD risk were identified in Sweden. This may be partially attributed to the selective participation of respondents who are, often, more healthy than the average person. However, although Sweden has no primary prevention program, another possible explanation could be that Sweden is a quick adopter of healthy lifestyle modifications as indicated, for example, by the fact that it is the first country with a daily smoking prevalence below $10 \%$ (17).

Differences were also observed in the acceptance of the selective prevention intervention, with the Czech Republic and Greece presenting the highest rates. Although these variations may be partially attributed to differences in the invitation processes implemented in each country, specifically for Greece this finding may reflect the generalized lack of systematic preventive activities provided by interdisciplinary teams in primary care, an issue reported since years (18). This may serve as a key message for health policy actions, especially in settings where coordinated reforms are evolving.

The implemented selective prevention intervention succeeded to engage $65-100 \%$ of participants in CVDrisk assessment, resulting in the identification of substantial proportions of high CVD-risk individuals (6.9-36.8\%). A similar Dutch study identified $64 \%$ of participants as being at high-risk, with $22 \%$ of them classified as newly diagnosed patients suffering from various conditions such as hypertension, hypercholesterolemia, and diabetes (19). Furthermore, our intervention's usefulness and feasibility where highly scored by participants, with significant proportions indicating that they, in response to the intervention, would be willing to try a lifestyle modification program for CMD-risk reduction (82.1-92.8\%). Although our results are not comparable across study sites due to contextual and procedural differences, they still contribute to the existing evidence regarding the necessity of CMD selective prevention actions within each study country.

Finally, the most commonly reported reason to change lifestyle behavior was willingness to be healthy (61.4-71.3\%). This finding is consistent with a recent systematic review conducted in the context of SPIM-EU, where prioritizing and feeling responsible for one's own health were recognized as facilitators for participating in a CMD health check in primary care (20).

\section{Strengths and limitations}

The main strength of this study was that was designed to include a set of characteristics and recommendations for a selective CMD prevention program, formed on the basis of an expert consensus. 
However, this study was not implemented without several limitations. Firstly, it was a descriptive study, without formal sample size calculation or statistical power to perform significance testing. As such, our study may have under-reported the true proportions of patients with increased CVD-risk. However, the aim of the study was to report on the feasibility of implementing selective prevention, rather than to identify the magnitude of CVD in primary care. Our design also does not allow for any type of comparisons or causality determination. Moreover, the purposive selection of study sites (in four out of five settings) does not allow for a random representation of either practices or patients. Although the overall intervention was followed in the same way in all countries, different risk assessment tools and communication strategies were used, according to the diverse local contexts. This may affect the comparability of participation and acceptance rates, as well as participants' assessment of the intervention. However, similar patterns have been reported in literature, with participation in health checks in primary care varying widely according to activity type (e.g. response rates ranging from a low $1.2 \%$ for an online risk estimation to a high of $84 \%$ for T2DM screening) $(19,20)$. Additionally, the selection of country-specific and locally validated risk assessment tools allowed for better adaptation of the intervention in the local contexts and aimed at enhancing their routine use in daily practice, even upon project completion. Furthermore, there are different barriers for CMD selective prevention in primary care, including structural, organizational and attitudinal factors, while the way of invitation may have a significant impact on patient participation (21).

\section{Study implications}

The action plan of the World Health Organization for the prevention and control of non-communicable diseases sets CMD-risk assessment and management among its five focus areas for priority interventions. Moreover, it acknowledges that further development of primary care services, together with public health services, is essential for improving health promotion, disease prevention, early detection and integrated care (2). The issue of an evidence-informed integration of public health and primary health care has been also discussed in local reports from Greece (22). Within this study, a directed implementation of a selective CMD prevention intervention in diverse primary care settings was conducted. Lessons learned can be used to refine similar interventions, accounting for specific factors that may influence implementation.

This study arrived timely in Europe, where strategies for CVD prevention vary across countries and systems. In countries like Greece major health care reforms are currently evolving in an effort to bring primary care in the forefront (23). In other settings like the Czech Republic, nationwide selective prevention programs checking for CMD risk of the population are already available (24). In counties such as the Netherlands, specific guidelines for selective CMD prevention have been developed by the Dutch College of GPs for all the population aged 45-70 years without any known risk factors (25). In Denmark, national strategies on selective CMD prevention are lacking. By contrast, the Vasterbotten Intervention Program in Sweden is integrated into primary care since 1985, with the population being invited to participate in a systematic risk-factor screening at the ages of 40,50 and 60 (26). 
As part of SPIM-EU, this study has ultimately contributed to the formation of an evidence-based toolbox for the design and implementation of selective primary care initiatives targeting CMD. In a recently published article, 12 general recommendations are illustrated on how to best design and implement CMD selective prevention (27).

\section{Conclusions}

This study affirmed the variations in the implementation of selective prevention interventions across Europe and underlined its importance in several countries, where CMD is a major public health issue. Findings indicate that preventive strategies need to be adapted to local contexts and adjusted to already existing programs, since their acceptance as well as potential benefit is highly dependent on that.

\section{Declarations}

Ethical approval: All participating countries applied and received approval from their local bioethics committees prior to study initiation [Czech Republic: Ethics Committee of the General University Hospital, Prague 1946/16 S-IV, Greece: Research and Development Committee of the Department of Programming and Development of Health Services and Social Solidarity of the 7th Health Region of Crete 13685/09-0817, Denmark: Registered on the University of Southern Denmark's list of approved studies journal nr. 18/5728, Sweden: Etikprövningsnämnden I Stockholm 2017/2053-31, the Netherlands: University Medical Center Utrecht 17-702/C). Together with their invitation, eligible participants were provided with a plain language statement, explaining the study aim and activities, and were given the opportunity to ask questions to the research team. All participants signed an informed consent form prior to their enrollment.

Competing interests: The authors report no conflicts of interest. The authors alone are responsible for the content and writing of the paper. The content of this manuscript presents the views of the authors only and is their sole responsibility. It cannot be considered to reflect the views of the European Commission and/or the Consumers, Health, Agriculture and Food Executive Agency or any other body of the European Union. The European Commission and the Agency do not accept any responsibility for use that may be made of the information it contains.

Funding: The study is part of the joint SPIM- EU project which received funding from the European Union's Health Programme (2014-2020) under grant agreement No. 663309.

Authors' contributions: CL was the leader of the respective work package of SPIM-EU, conceived the study design, supervised the study implementation and contributed to the writing of this paper. MA provided scientific input for this manuscript and contributed to the interpretation of results and the writing of this paper. AB performed the statistical analyses and drafted the initial manuscript. ACC and PW took part in planning of the study and critically revised the manuscript. HG collected the Swedish data and critically revised the manuscript. AA, ALS, TT, BS, NK, FGS, MH, JK, JS and NdW took part in the planning and data collection of the study and critically revised the manuscript. 


\section{References}

1. Townsend N, Wilson L, Bhatnagar P, Wickramasinghe K, Rayner M, Nichols M. Cardiovascular disease in Europe: epidemiological update 2016. European Heart Journal. 2016;37(42):3232-45.

2. Global Action Plan for the Prevention and Control of NCDs 2013-2020. 2019.

3. James WP. The epidemiology of obesity: the size of the problem. Journal of Internal Medicine. 2008;263(4):336-52.

4. Yusuf S, Reddy S, Ounpuu S, Anand S. Global burden of cardiovascular diseases: Part II: variations in cardiovascular disease by specific ethnic groups and geographic regions and prevention strategies. Circulation. 2001;104(23):2855-64.

5. Deaton C, Froelicher ES, Wu LH, Ho C, Shishani K, Jaarsma T. The global burden of cardiovascular disease. Journal of Cardiovascular Nursing. 2011;26(4 Suppl):S5-14.

6. Piepoli MF, Hoes AW, Agewall S, Albus C, Brotons C, Catapano AL, et al. 2016 European guidelines on cardiovascular disease prevention in clinical practice. The Sixth Joint Task Force of the European Society of Cardiology and Other Societies on Cardiovascular Disease Prevention in Clinical Practice (constituted by representatives of 10 societies and by invited experts. Developed with the special contribution of the European Association for Cardiovascular Prevention \& Rehabilitation). European Heart Journal. 2016;37(29):2315-2381.

7. Mrazek PJ, Haggerty RJ, et al. Reducing Risks for Mental Disorders: Frontiers for Preventive Intervention Research. Washington (DC) National Academies Press (US). 1994.

8. Unal B, Critchley JA, Capewell S. Modelling the decline in coronary heart disease deaths in England and Wales, 1981-2000: comparing contributions from primary prevention and secondary prevention. British Medical Journal. 2005;331(7517):614.

9. Si S, Moss JR, Sullivan TR, Newton SS, Stocks NP. Effectiveness of general practice-based health checks: a systematic review and meta-analysis. The British journal of general practice: Journal of the Royal College of General Practitioners. 2014;64(618):e47-53.

10. de Waard AM, Hollander M, Korevaar JC, Nielen MMJ, Carlsson AC, Lionis C, et al. Selective prevention of cardiometabolic diseases: activities and attitudes of general practitioners across Europe. European Journal of Public Health. 2019;29(1):88-93.

11. Král N, de Waard AM, Schellevis FG, Korevaar JC, Lionis C, Carlsson AC, et al. What should selective cardiometabolic prevention programmes in European primary care look like? A consensus-based design by the SPIM-EU group. European Journal of General Practice. 2019;25:101-108.

12. Conroy RM, Pyorala K, Fitzgerald AP, Sans S, Menotti A, De Backer G, et al. SCORE project group: Estimation of ten-year risk of fatal cardiovascular disease in Europe: the SCORE project. European Heart Journal. 2003; 24:987-1003.

13. Karjalainen T, Adiels M, Björck L, Cooney MT, Graham I, Perk J, et al. An evaluation of the performance of SCORE Sweden 2015 in estimating cardiovascular risk: the Northern Sweden MONICA Study 1999-2014. European Journal of Preventive Cardiology. 2017;24(1):103-10. 
14. Larsen LB, Sonderlund AL, Sondergaard J, Thomsen JL, Halling A, Hvidt NC, et al., Targeted prevention in primary care aimed at lifestyle-related diseases: a study protocol for a non-randomised pilot study. BMC Family Practice. 2018;19(1):124.

15. Dekker JM, Alssema M, Janssen PGH, Van der Paardt M, Festen CSS, Van Oosterhout MJW. NHGstandard Prevention Consultation cardiometabolic risk from the Dutch College of General Practitioners [in Dutch]. 2011;54(3):138-155.

16. OECD statistics. Available from: https://www.oecd-ilibrary.org/docserver/9789264283404en.pdf? expires=1572474646\&id=id\&accname=guest\&checksum=A2A41FB427AA628DB7F20BF18547D101.

17. Available from: https://www.folkhalsomyndigheten.se/folkhalsorapportering-statistik/tolkadrapportering/folkhalsans-utveckling/levnadsvanor/tobaksrokning-daglig/

18. Brotons C, Björkelund C, Bulc M, Ciurana R, Godycki-Cwirko M, Jurgova E, et al. Prevention and health promotion in clinical practice: the views of general practitioners in Europe. Preventive Medicine. 2005; 40(5): 595-601.

19. Van der Meer V, Nielen MM, Drenthen AJ, Van Vliet M, Assendelft WJ, Schellevis FG. Cardiometabolic prevention consultation in the Netherlands: screening uptake and detection of cardiometabolic risk factors and diseases-a pilot study. BMC Family Practice. 2013;14:29.

20. de Waard AM, Wandell PE, Holzmann MJ, Korevaar JC, Hollander M, Gornitzki C, et al. Barriers and facilitators to participation in a health check for cardiometabolic diseases in primary care: A systematic review. European Journal of Preventive Cardiology. 2018;25(12):1326-40.

21. Wändell P, de Waard A-K, Holzmann M, Gornitzki C, Lionis C, de Wit N, et al. Barriers and facilitators among health professionals in primary care to prevention of cardiometabolic diseases. A systematic review. Family Practice. 2018; 35(4):383-398

22. Lionis C, Petelos E, Papadakis S, Tsiligianni I, Anastasaki M, Angelaki A, et al. Towards evidenceinformed integration of public health and primary health care: experiences from Crete. WHO Public Health Panorama. 2018; 4:699-714.

23. Greek health reform: opening of new primary health care units. World Health Organization. 2017.

24. Available from: https://www.vzp.cz/pojistenci/prevence/preventivni-prohlidky [in Czech].

25. Dekker JM, Alssema M, Janssen PG, Goudswaard LN, werkgroup NHG. Summary of the practice guideline 'The Prevention Visit' from the Dutch College of General Practitioners. Nederlands Tijdschrift voor Geneeskunde. 2011;155(18):A3428.

26. Norberg M, Wall S, Boman K, Weinehall L. The Vasterbotten Intervention Programme: background, design and implications. Global Health Action. 2010;3.

27. Sonderlund AL, Thilsing T, Korevaar J, Hollander M, Lionis C, Schellevis F, et al. An evidence-based toolbox for the design and implementation of selective-prevention primary-care initiatives targeting cardio-metabolic disease. Preventive Medicine Reports. 2019; 16: 100979

\section{Tables}


Table 1. Demographic characteristics of individuals accepting invitation per country.

\begin{tabular}{|c|c|c|c|c|c|}
\hline Variable & $\begin{array}{l}\text { CzechRepublic } \\
(\mathrm{N}=200)\end{array}$ & $\begin{array}{c}\text { Denmark } \\
(\mathrm{N}=62)\end{array}$ & $\begin{array}{c}\text { Greece } \\
(\mathrm{N}=107)\end{array}$ & $\begin{array}{l}\text { Netherlands } \\
(\mathrm{N}=66)\end{array}$ & $\begin{array}{l}\text { Sweden } \\
(\mathrm{N}=39)\end{array}$ \\
\hline \multicolumn{6}{|l|}{ Gender, $n(\%)$} \\
\hline Female & $121(60.5)$ & $29(46.8)$ & $\begin{array}{c}34 \\
(59.8)\end{array}$ & $36(54.5)$ & $27(69.2)$ \\
\hline Male & $79(39.5)$ & $33(53.2)$ & $\begin{array}{c}43 \\
(40.2)\end{array}$ & $30(45.5)$ & $\begin{array}{c}12 \\
(30.8)\end{array}$ \\
\hline Age (years), mean (SD) & $50.0(8.8)$ & $\begin{array}{l}55.5 \\
(6.3)\end{array}$ & $\begin{array}{l}52.7 \\
(8.5)\end{array}$ & $54.0(10.3)$ & $\begin{array}{l}51.1 \\
(6.3)\end{array}$ \\
\hline \multicolumn{6}{|l|}{ Education, $n(\%)$} \\
\hline None & $0(0)$ & $0(0)$ & $5(4.7)$ & $0(0)$ & $0(0)$ \\
\hline Primary & $1(0.5)$ & $1(1.9)$ & $\begin{array}{c}19 \\
(17.8)\end{array}$ & $1(1.5)$ & $0(0)$ \\
\hline Secondary & $34(17.2)$ & $8(14.8)$ & $\begin{array}{c}52 \\
(48.6)\end{array}$ & $12(18.2)$ & $0(0)$ \\
\hline College/University & $163(82.3)$ & $45(83.4)$ & $31(29)$ & $53(80.3)$ & $39(100)$ \\
\hline \multicolumn{6}{|l|}{ Work status, $n(\%)$} \\
\hline Full time & $131(65.5)$ & $37(59.7)$ & $\begin{array}{c}62 \\
(57.9)\end{array}$ & $32(48.5)$ & $\begin{array}{c}36 \\
(92.3)\end{array}$ \\
\hline Part time & $30(15)$ & $11(17.7)$ & $\begin{array}{c}22 \\
(20.6)\end{array}$ & $17(25.8)$ & $2(5.1)$ \\
\hline Pensioner & $11(5.5)$ & $8(12.9)$ & $9(8.4)$ & $12(18.2)$ & $1(2.6)$ \\
\hline Unemployed & $4(2)$ & $4(6.5)$ & $\begin{array}{c}14 \\
(13.1)\end{array}$ & $3(4.5)$ & $0(0)$ \\
\hline Disabled & $24(12)$ & $2(3.2)$ & $0(0)$ & $2(3)$ & $0(0)$ \\
\hline \multicolumn{6}{|l|}{ Health insurance, $n(\%)$} \\
\hline Yes & $192(96)$ & $26(41.9)$ & $\begin{array}{c}84 \\
(79.2)\end{array}$ & $66(100)$ & $\begin{array}{c}27 \\
(69.2)\end{array}$ \\
\hline No & $3(1.5)$ & $4(6.5)$ & $\begin{array}{c}21 \\
(19.8)\end{array}$ & $0(0)$ & $7(17.9)$ \\
\hline Not applicable & $5(2.5)$ & $32(51.6)$ & $1(0.9)$ & $0(0)$ & $5(12.8)$ \\
\hline \multicolumn{6}{|c|}{$\begin{array}{l}\text { Income compared to country's average, } \\
n(\%)\end{array}$} \\
\hline Lower & $44(22)$ & $21(34.4)$ & $\begin{array}{c}67 \\
(62.6)\end{array}$ & $5(7.7)$ & $3(7.7)$ \\
\hline Corresponding & $61(30.7)$ & $22(36.1)$ & $\begin{array}{c}23 \\
(21.5)\end{array}$ & $35(53.8)$ & $8(20.5)$ \\
\hline Higher & $84(42.2)$ & $17(27.9)$ & $0(0)$ & $24(36.9)$ & $\begin{array}{c}24 \\
(61.5)\end{array}$ \\
\hline Don't know & $10(5)$ & $1(1.6)$ & $\begin{array}{c}17 \\
(15.9)\end{array}$ & $1(1.5)$ & 4 (10.3) \\
\hline
\end{tabular}


Table 2. Lifestyle-related cardio-metabolic risk factors of individuals accepting invitation per country. 


\begin{tabular}{|c|c|c|c|c|c|}
\hline Variable & $\begin{array}{l}\text { Czech } \\
\text { Republic } \\
(\mathrm{n}=200)\end{array}$ & $\begin{array}{l}\text { Denmark } \\
(\mathrm{N}=62)\end{array}$ & $\begin{array}{c}\text { Greece } \\
(\mathrm{N}=107)\end{array}$ & $\begin{array}{l}\text { Netherlands } \\
(\mathrm{N}=66)\end{array}$ & $\begin{array}{l}\text { Sweden } \\
(\mathrm{N}=39)\end{array}$ \\
\hline \multicolumn{6}{|l|}{ Smoking, $n(\%)$} \\
\hline Never & $122(61)$ & $24(40)$ & $\begin{array}{c}35 \\
(32.7)\end{array}$ & $36(56.3)$ & $\begin{array}{c}28 \\
(71.8)\end{array}$ \\
\hline Quit over 6 months & $34(17)$ & $20(33.3)$ & $16(15)$ & $22(34.4)$ & $8(20.5)$ \\
\hline Quit less than 6 months & $3(1.5)$ & $1(1.7)$ & $1(0.9)$ & $1(1.6)$ & $\begin{array}{c}1 \\
(2.6 \%)\end{array}$ \\
\hline Occasionally & $13(6.5)$ & $5(8.3)$ & $9(8.4)$ & $3(4.7)$ & $0(0)$ \\
\hline Everyday & $28(14)$ & 10 (16.7) & $46(43)$ & $2(3.1)$ & $2(5.1)$ \\
\hline Drinks/week, median (IQR) & $2(6)$ & $4(8)$ & $7(9)$ & $2(7)$ & $3(5)$ \\
\hline \multicolumn{6}{|l|}{$\begin{array}{l}\text { Consumption of } \geq 4 \text { (female) or } 5 \text { (male) } \\
\text { drinks on a single occasion, } n(\%)\end{array}$} \\
\hline Once a week & $29(14.5)$ & $\begin{array}{c}8 \\
(12.9 \%)\end{array}$ & $\begin{array}{c}12 \\
(11.3)\end{array}$ & $8(12.5)$ & $4(10.3)$ \\
\hline Once a month & $48(24)$ & $18(29)$ & $\begin{array}{c}11 \\
(10.4)\end{array}$ & $8(12.5)$ & $8(20.5)$ \\
\hline Rarely & $86(43)$ & $29(46.8)$ & $\begin{array}{c}31 \\
(29.2)\end{array}$ & $25(39.1)$ & $\begin{array}{c}24 \\
(61.5)\end{array}$ \\
\hline Never & $33(16)$ & $3(4.8)$ & $\begin{array}{c}49 \\
(46.2)\end{array}$ & $21(32.8)$ & $3(7.7)$ \\
\hline \multicolumn{6}{|l|}{ Physical activity, $n(\%)$} \\
\hline Sedentary (rarely/never) & $29(14.7)$ & $5(8.1)$ & $\begin{array}{c}21 \\
(19.6)\end{array}$ & $8(12.1)$ & $4(10.3)$ \\
\hline Underactive (light/moderate - not weekly) & $62(31.6)$ & $12(25)$ & $\begin{array}{c}51 \\
(48.1)\end{array}$ & $13(20)$ & $\begin{array}{c}10 \\
(25.6)\end{array}$ \\
\hline Regular-light ( light, weekly) & $146(74.1)$ & $38(67.9)$ & $\begin{array}{c}75 \\
(70.1)\end{array}$ & $39(60.9)$ & $\begin{array}{c}33 \\
(84.6)\end{array}$ \\
\hline $\begin{array}{l}\text { Regular-moderate (moderate, weekly, } \leq 30 \\
\text { mins/day) }\end{array}$ & $91(46.4)$ & $29(52.7)$ & $\begin{array}{c}36 \\
(33.6)\end{array}$ & $29(44.6)$ & $\begin{array}{c}22 \\
(56.4)\end{array}$ \\
\hline $\begin{array}{l}\text { Regular-vigorous (vigorous, weekly, } \leq \\
\text { 20mins/day) }\end{array}$ & $59(30.1)$ & $12(23.5)$ & $10(9.3)$ & 16 (24.2) & $16(41)$ \\
\hline $\begin{array}{l}\text { Active-moderate ( } 30 \text { mins moderate for } \geq 5 \\
\text { days/week) }\end{array}$ & 58 (29.4) & $26(47.3)$ & $\begin{array}{c}13 \\
(12.1)\end{array}$ & 28 (42.4) & $\begin{array}{c}15 \\
(38.5)\end{array}$ \\
\hline $\begin{array}{l}\text { Active-vigorous (20 mins vigorous for } \geq 3 \\
\text { days/week) }\end{array}$ & $33(16.8)$ & $11(20)$ & $10(9.3)$ & $11(17.5)$ & $\begin{array}{c}11 \\
(28.2) \\
\end{array}$ \\
\hline \multicolumn{6}{|l|}{ Vegetable consumption, $n(\%)$} \\
\hline$\leq$ once/week & $22(11.1)$ & $2(3.2)$ & $\begin{array}{c}32 \\
(29.9)\end{array}$ & $0(0)$ & $2(5.1)$ \\
\hline A few times/week & $89(44.7)$ & $22(35.5)$ & $\begin{array}{c}62 \\
(57.9)\end{array}$ & $13(20)$ & $5(12.8)$ \\
\hline Once/day & 71 (35.7) & $25(40.3)$ & $\begin{array}{c}12 \\
(11.2)\end{array}$ & $46(70.8)$ & $\begin{array}{c}24 \\
(61.5)\end{array}$ \\
\hline$\geq$ twice/day & $17(8.5)$ & $13(21)$ & $1(0.9)$ & $6(9.2)$ & $8(20.5)$ \\
\hline
\end{tabular}




\begin{tabular}{|c|c|c|c|c|c|}
\hline \multicolumn{6}{|c|}{ Fruit consumption, $n(\%)$} \\
\hline sonce/week & $21(10.5)$ & $9(14.5)$ & $\begin{array}{c}27 \\
(25.2)\end{array}$ & $2(3.1)$ & $5(12.8)$ \\
\hline A few times/week & $71(35.5)$ & $24(38.7)$ & $\begin{array}{c}57 \\
(53.3)\end{array}$ & $17(26.2)$ & $\begin{array}{c}12 \\
(30.8)\end{array}$ \\
\hline Once/day & $83(41.5)$ & $22(35.5)$ & $\begin{array}{c}19 \\
(17.8)\end{array}$ & $30(46.2)$ & $\begin{array}{c}15 \\
(38.5)\end{array}$ \\
\hline$\geq$ twice/day & $25(12.5)$ & $7(11.3)$ & $4(3.7)$ & $16(24.6)$ & $7(17.9)$ \\
\hline \multicolumn{6}{|c|}{ Fish consumption, $n(\%)$} \\
\hline A few times/month & $123(62.1)$ & $31(50)$ & $\begin{array}{c}72 \\
(67.3)\end{array}$ & $17(26.2)$ & $6(15.4)$ \\
\hline Once/week & $56(28.3)$ & $19(30.6)$ & $\begin{array}{c}26 \\
(24.3)\end{array}$ & $33(50.8)$ & $\begin{array}{c}14 \\
(35.9)\end{array}$ \\
\hline Twice/week & $13(6.6)$ & $9(14.5)$ & $9(8.4)$ & $12(18.5)$ & $\begin{array}{c}13 \\
(33.3)\end{array}$ \\
\hline$\geq$ three times/week & $6(3)$ & $3(4.8)$ & $0(0)$ & $3(4.6)$ & $6(15.4)$ \\
\hline \multicolumn{6}{|c|}{ Pastry consumption, $n(\%)$} \\
\hline$\leq$ once/week & $28(14)$ & $16(25.8)$ & $\begin{array}{c}21 \\
(20.2)\end{array}$ & $18(27.7)$ & $\begin{array}{c}19 \\
(48.7)\end{array}$ \\
\hline A few times/week & $59(29.5)$ & $25(40.3)$ & $\begin{array}{c}32 \\
(30.8)\end{array}$ & $27(40.9)$ & $\begin{array}{c}15 \\
(38.5)\end{array}$ \\
\hline Nearly every day & $41(20.5)$ & $15(24.2)$ & $\begin{array}{c}20 \\
(19.2)\end{array}$ & $9(13.8)$ & $5(12.8)$ \\
\hline Everyday & $72(36)$ & $6(9.7)$ & $\begin{array}{c}31 \\
(29.8)\end{array}$ & $11(16.9)$ & $0(0)$ \\
\hline
\end{tabular}

Table3. Cardio-vascular risk scores among individuals accepting risk assessment by country and tool used. 


\begin{tabular}{|c|c|c|c|c|c|}
\hline Score & $\begin{array}{l}\text { CzechRepublic } \\
(\mathrm{N}=174)\end{array}$ & $\begin{array}{c}\text { Denmark } \\
(\mathrm{N}=58)\end{array}$ & $\begin{array}{l}\text { Greece } \\
(\mathrm{N}=70)\end{array}$ & $\begin{array}{l}\text { Netherlands } \\
(\mathrm{N}=57)\end{array}$ & $\begin{array}{l}\text { Sweden } \\
(\mathrm{N}=39)\end{array}$ \\
\hline Heart SCORE, median (25\%-75\%) & $1(0-2)$ & & $\begin{array}{l}1(0- \\
3)\end{array}$ & & \\
\hline Heart SCORE $\geq 5 \%, n(\%)$ & $12(6.9)$ & & $\begin{array}{c}8 \\
(11.4)\end{array}$ & & \\
\hline Heart SCORE $\geq 10 \%, n(\%)$ & $4(2.3)$ & & $3(4.3)$ & & \\
\hline Svenska Score, median (25\%-75\%) & & & & & $\begin{array}{c}0(0- \\
1)\end{array}$ \\
\hline Svenska Score $\geq 5 \%, n(\%)$ & & & & & $0(0)$ \\
\hline Svenska Score $\geq 10 \%, n(\%)$ & & & & & $0(0)$ \\
\hline $\begin{array}{l}\text { Modified Heartscore BMI score, median } \\
(25 \%-75 \%)\end{array}$ & & & & & \\
\hline $\begin{array}{l}\text { Modified Heartscore BMI score } \\
\geq 5 \%, n(\%)\end{array}$ & & $5(8.6)$ & & & \\
\hline PC CMR, median (25\%-75\%) & & & & $\begin{array}{l}22(13.5- \\
39.5)\end{array}$ & \\
\hline $\begin{array}{l}\text { PC CMR } \geq 23 \% \text { (men) or PC CMR } \\
\geq 19 \% \text { (women), } n(\%)\end{array}$ & & & & $21(36.8)$ & \\
\hline
\end{tabular}

Abbreviations: PC CMR: Dutch Prevention Consultation Cardio-metabolic Risk

\section{Supplementary Figure Legend}

Supplementary Figure. Study recruitment flowchart.

\section{Figures}




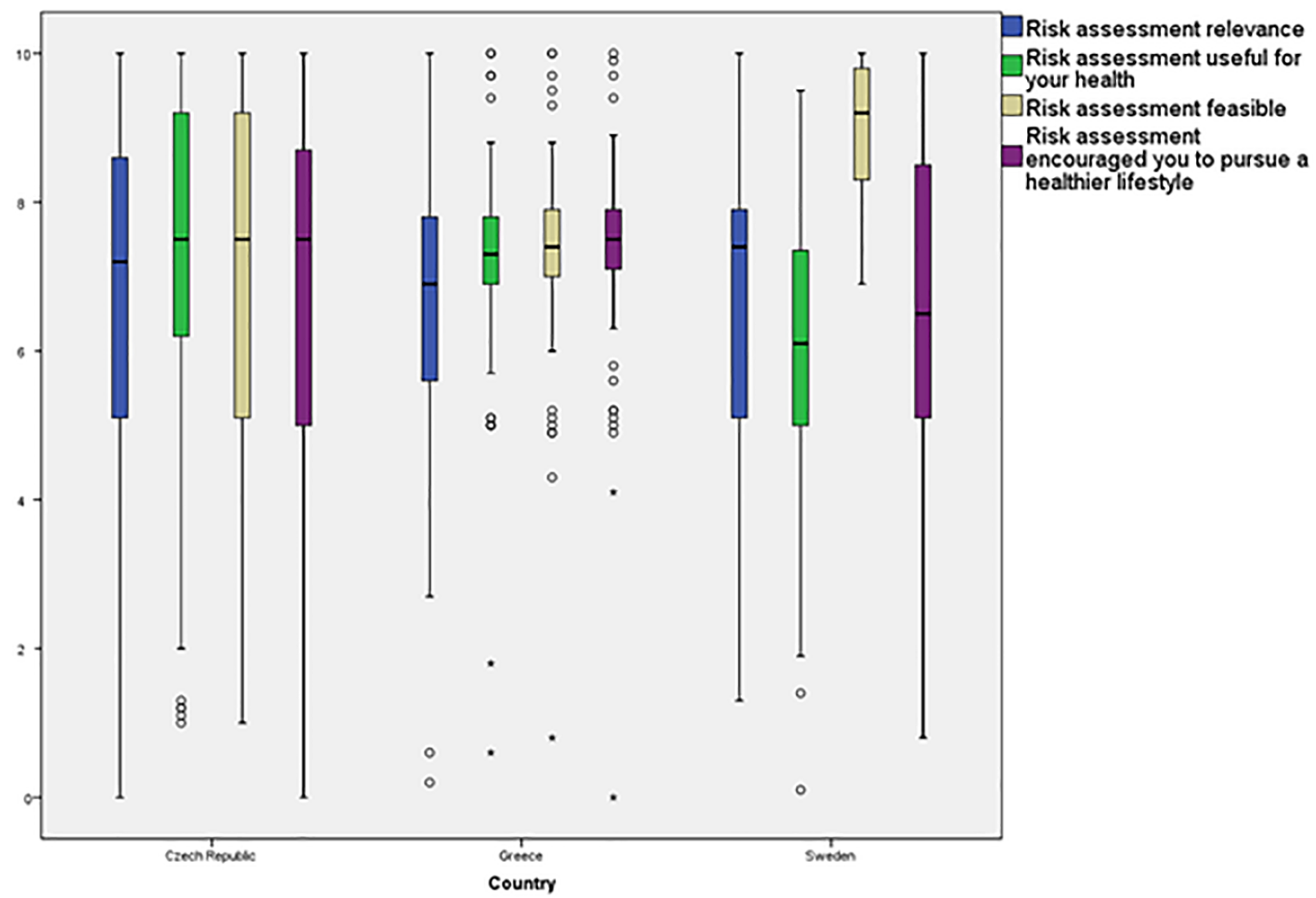

Figure 1

Participants' evaluation of the risk assessment intervention. Figure 1 legend: Participants from Denmark and the Netherlands did not answer evaluation questions, despite their invitation to do so. 


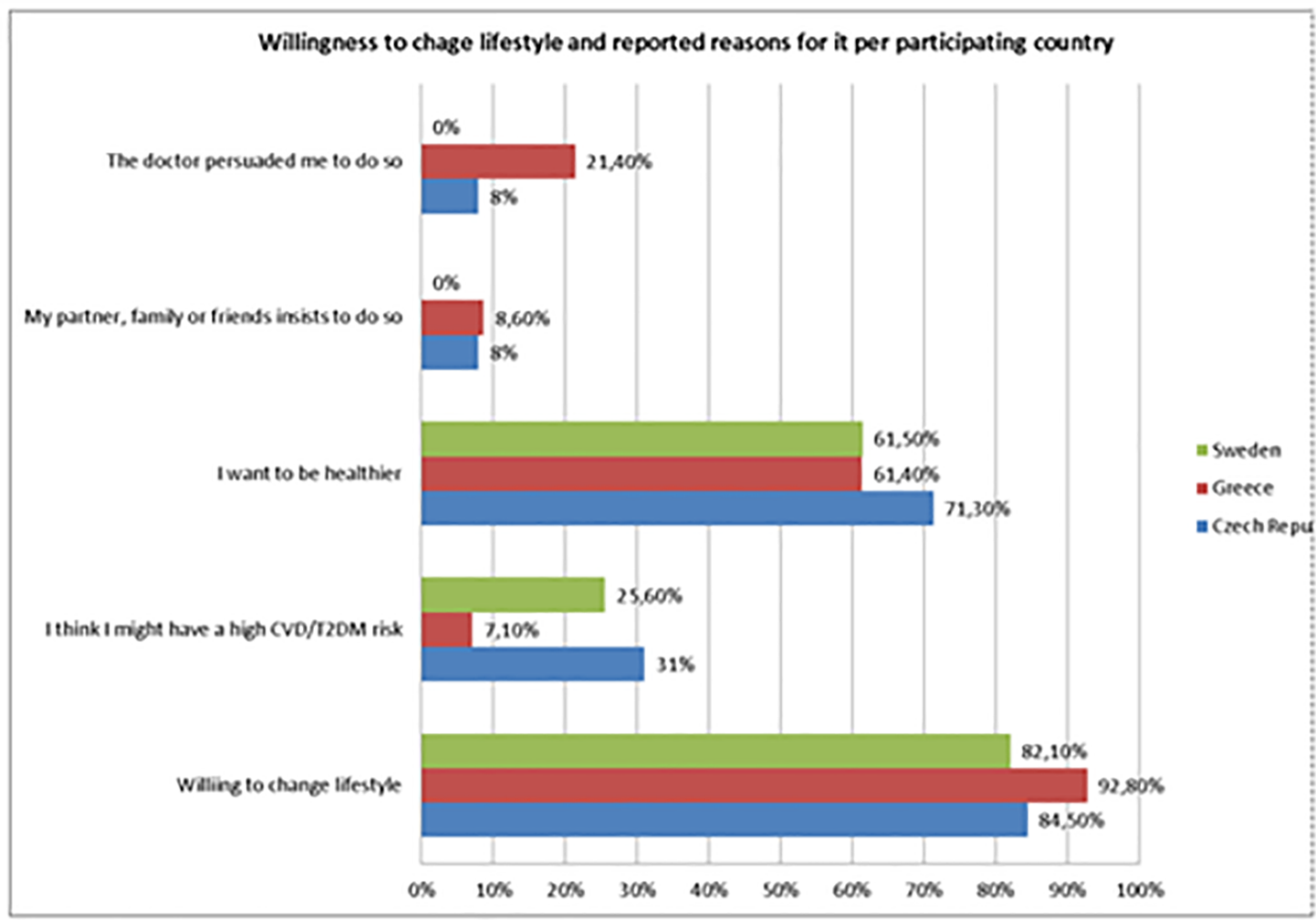

\section{B}

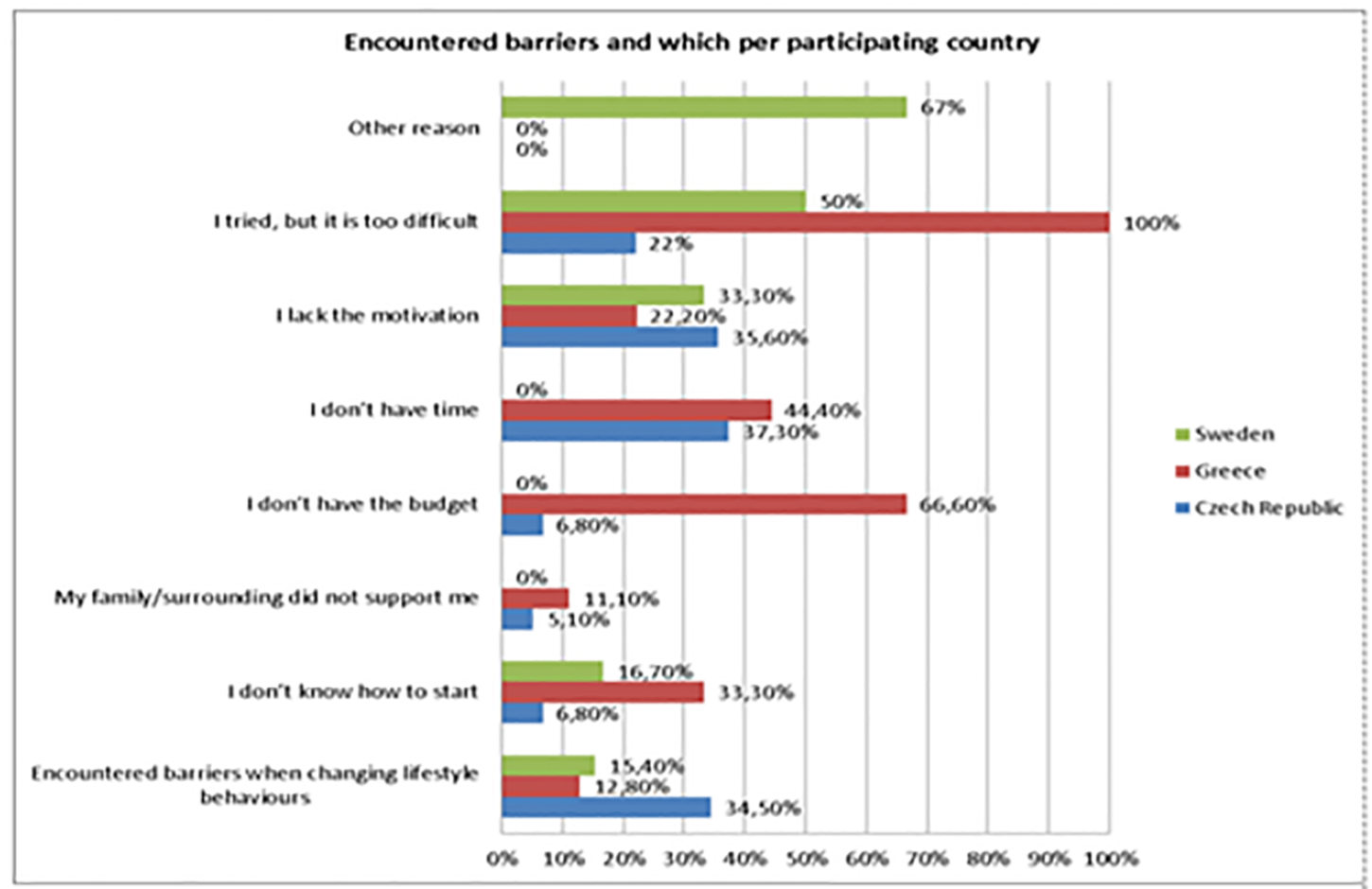

\section{Figure 2}

Willingness (3A) and barriers (3B) towards changing lifestyle among participants accepting risk assessment. Figure 2 legend: Despite invitation, participants from Denmark and the Netherlands did not answer evaluation questions. Abbreviations: CVD: cardiovascular disease, T2DM: type-II diabetes mellitus

\section{Supplementary Files}


This is a list of supplementary files associated with this preprint. Click to download.

- SupplementaryFigure.tif

- SupplementaryTable.docx

- STROBEchecklist.docx 